CLINICAL RESEARCH ARTICLE

\title{
Rituximab modulates T- and B-lymphocyte subsets and urinary CD80 excretion in patients with steroid-dependent nephrotic syndrome
}

\author{
Divya Bhatia ${ }^{1}$, Aditi Sinha ${ }^{1}$, Pankaj Hari ${ }^{1}$, Shailaja Sopory ${ }^{2}$, Savita Saini ${ }^{1}$, Mamta Puraswani ${ }^{1}$, Himanshi Saini ${ }^{1}$, \\ Dipendra K Mitra ${ }^{3}$ and Arvind Bagga ${ }^{1}$
}

BACKGROUND: Rituximab, a monoclonal antibody targeting B lymphocytes, effectively sustains remission in steroid-dependent nephrotic syndrome (SDNS). We studied its effects on lymphocyte subsets and urinary CD80 excretion (uCD80) in patients with SDNS.

METHODS: Blood and urine samples were collected from 18 SDNS patients before rituximab, and after 1 month and 1 year or at first relapse. T and B lymphocytes and UCD80 were determined by flow cytometry and ELISA, respectively.

RESULTS: Treatment was associated with reduction in counts of Th17, Th2, and memory T cells, and increased T-regulatory (Treg) cells. The Th17/Treg ratio declined from baseline (median 0.6$)$ to 1 month $(0.2, P=0.006)$ and increased during relapse $(0.3, P=$ 0.016). Ratios of Th1/Th2 cells at baseline, 1 month after rituximab, and during relapse were 7.7, $14.0(P=0.0102)$, and 8.7, respectively. uCD80 decreased 1 month following rituximab (45.5 vs. $23.0 \mathrm{ng} / \mathrm{g}$ creatinine; $P=0.0039$ ). B lymphocytes recovered earlier in relapsers $(60.0$ vs.183.0 days; $P<0.001)$. Memory $B$ cells were higher during relapse than remission $(29.7$ vs.18.0 cells/ $\mu \mathrm{L}$; $P=0.029$ ).

CONCLUSION: Rituximab-induced sustained remission and B-cell depletion was associated with reduced numbers of Th17 and Th2 lymphocytes, and increased Treg cells; these changes reversed during relapses. Recovery of B cells and memory B cells predicted the occurrence of a relapse.

Pediatric Research (2018) 84:520-526; https://doi.org/10.1038/s41390-018-0088-7

\section{INTRODUCTION}

While most patients with a nephrotic syndrome respond to corticosteroids, approximately one-half of patients have a steroiddependent nephrotic syndrome (SDNS) or a frequently relapsing course. ${ }^{1}$ Strong evidence links perturbations of cell-mediated immunity to the pathogenesis of steroid-sensitive nephrotic syndrome, including (i) the absence of humoral deposits in glomeruli; ${ }^{2}$ (ii) induction of proteinuria in rats after administration of T-cell supernatant from patients with the illness; ${ }^{3}$ (iii) remission following measles, which downregulates cell-mediated immunity; ${ }^{4}$ (iv) association of a nephrotic syndrome with Hodgkin lymphoma; ${ }^{5}$ and $(v)$ response to treatment with agents that specifically inhibit $T$ (steroids and calcineurin inhibitors) or $B$ (cyclophosphamide, mycophenolate mofetil, and rituximab) lymphocytes function.'

Reports of increased circulating levels of IgE, normal IgG4 (with decreased $\lg G 1$ and $\lg G 2$ ), and association with atopy suggest Th2 cytokine bias. ${ }^{6}$ Relapses of a nephrotic syndrome are also associated with a reduced proportion of T-regulatory (Treg) cells and an increased ratio of Th17/Treg lymphocytes., 7 A similar imbalance between interleukin (IL)-17-producing Th17 cells and FoxP3-expressing Treg cells is considered important in inflammatory disorders, including rheumatoid arthritis and multiple sclerosis., 9
Treg cells-derived soluble cytotoxic T-lymphocyte-associated protein-4 (CTLA-4) and IL-10 are proposed to negatively regulate the expression of CD80 or B7.1 on antigen-presenting cells. ${ }^{11}$ The expression of CD80 on podocytes and its urinary excretion is reported to increase during relapses of a nephrotic syndrome. ${ }^{12}$ Thus, it is suggested that downregulation of Treg cells during a nephrotic syndrome relapse might contribute to increased urinary excretion of CD80. Rituximab, a chimeric monoclonal antibody directed against CD20, an antigen expressed by almost all B cells, results in short-term depletion of $B$ lymphocytes. ${ }^{13}$ Rituximab is considered an effective treatment for malignancies, chiefly $B$ cell non-Hodgkin lymphoma ${ }^{14}$ and various immune-mediated diseases, ${ }^{15}$ where it acts primarily by depleting B cells, reducing Th17 cells, and increasing the proportions of Treg cells. ${ }^{16}$

Experience over the past decade confirms that therapy with rituximab effectively sustains remission in patients with SDNS; ${ }^{17,18}$ reducing the need for corticosteroids and other immunosuppressive medications. ${ }^{19,20}$ Despite reports on efficacy, it is unclear how this B-cell-depleting agent enables remission in SDNS. Studies in rheumatoid arthritis ${ }^{21}$ and systemic lupus erythematosus ${ }^{15}$ show that rituximab-induced B-cell depletion chiefly affects T-lymphocyte subsets. Information on the immune effects of rituximab and the association of the duration of B-cell depletion with remission in nephrotic syndrome patients is limited ${ }^{22,23 .}$ We

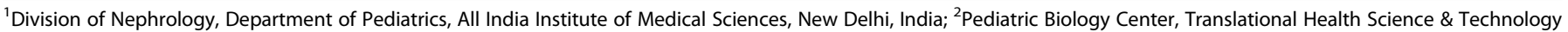
Institute, Faridabad, India and ${ }^{3}$ Department of Transplant Immunology \& Immunogenetics, All India Institute of Medical Sciences, New Delhi, India

Correspondence: Arvind Bagga (arvindbagga@hotmail.com)

Received: 4 April 2018 Revised: 29 May 2018 Accepted: 5 June 2018

Published online: 9 July 2018 


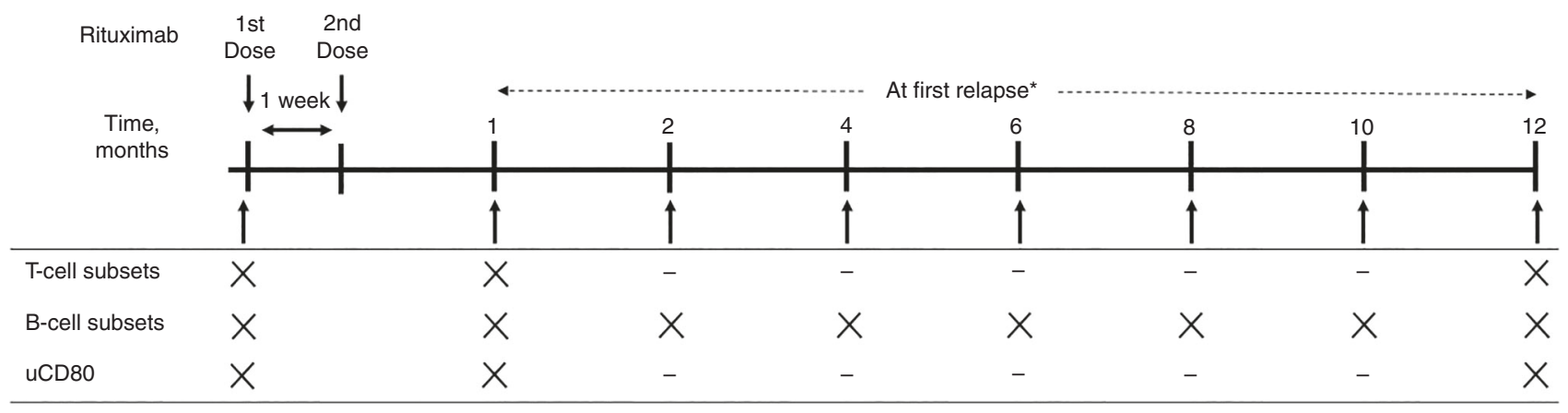

${ }^{*} \mathrm{~T}$ and B cell subsets and uCD80 at three time points; only B cell subsets at serial timepoints

Fig. 1 Time points of blood and urine sample collection for lymphocyte ( $T$ and B-cell) subsets and urinary CD80 (uCD80)

prospectively determined the effect of rituximab on T- and Blymphocyte subsets in patients with SDNS.

\section{METHODS}

Patients and samples

Peripheral blood and urine were collected from 18 patients with SDNS during corticosteroid-induced remission. Following the administration of two doses of rituximab, $375 \mathrm{mg} / \mathrm{m}^{2}$ each, 1-week apart, samples were again collected after 1 and 12 months, or at occurrence of a relapse (Fig. 1). Prednisolone was tapered by $0.25 \mathrm{mg} / \mathrm{kg}$ every $1-2$ weeks after rituximab administration and discontinued by 3-5 months. During 12-months follow-up, relapses were treated with daily prednisolone until remission and then on alternate days for 4 weeks, and discontinued. Patients did not receive any other immunosuppressive medications during the year. B lymphocytes were considered completely depleted when $\mathrm{CD} 19^{+}$cells were $<1 \%$ of lymphocytes. These cells were measured every 2 months for up to 12 months. Controls were 18 healthy children, who visited the hospital for a minor surgery and had no renal or immune-mediated disorders, or acute or chronic infections. Patients with steroid resistance, congenital or secondary nephrotic syndrome, or impaired renal function (estimated GFR $<60 \mathrm{ml} / \mathrm{min} / 1.73 \mathrm{~m}^{2}$ ) or patients who had received therapy with cyclophosphamide during the previous 6 months were excluded. The study was approved by the ethics committee of the All India Institute of Medical Sciences; written, informed parental consent was obtained before enrolment of each patient.

Cell isolation and culture

Peripheral blood mononuclear cells (PBMCs) were isolated from heparinized blood using Ficoll-Hypaque (Axis-Shield, Oslo, Norway) density-gradient centrifugation method. Blood diluted in phosphate-buffered saline (PBS, 1:1) was layered on the surface of Ficoll at a ratio of $2: 1$ and centrifuged at $670 \mathrm{~g}$ for $20 \mathrm{~min}$ at $20^{\circ} \mathrm{C}$ with no breaks. The cells were harvested from the Ficoll interface, washed, and seeded at a concentration of $2 \times 10^{6}$ cells $/ \mathrm{ml}$ in a 24well culture plate (Corning Life Sciences, Big Flats, NY). The culture medium was RPMI-1640 supplemented with $10 \%$ fetal bovine serum (Invitrogen, Burlington, ON), 0.03\% L-glutamine, $0.36 \%$ HEPES buffer, and $1 \mu \mathrm{M} \beta$-mercaptoethanol. Cells were stimulated with phorbol myristate acetate (PMA, $50 \mathrm{ng} / \mathrm{ml}$ ), ionomycin $(500 \mathrm{ng} / \mathrm{ml})$, and monensin $(2 \mu \mathrm{M} / \mathrm{ml})$ and incubated at $37^{\circ} \mathrm{C}$ for $4 \mathrm{~h}$ with $5 \% \mathrm{CO}_{2}$ and $90 \%$ humidity. All reagents, except fetal bovine serum, were procured from Sigma-Aldrich (St. Louis, MO).

\section{Multicolor flow cytometry}

Characterization of T- and B-lymphocyte subsets was performed using flow cytometry. The frequencies of B cells and CD4, CD8, and Treg cells were determined on unstimulated whole blood.
EDTA blood $(100 \mu \mathrm{l})$, aliquoted into FACS tubes (BD Biosciences, San Jose, CA), was surface-labeled with the following antibodies in multiple cocktails: phycoerythrin (PE)-conjugated anti-CD19 (BD Biosciences), allophycocyanin (APC)-conjugated anti-CD27 (Biolegend, San Diego, CA), peridinin chlorophyll protein-cyanine (PerCp-Cy) 5.5-conjugated anti-CD5 (Biolegend), fluorescein isothiocyanate (FITC)-conjugated anti-CD4 (BD Biosciences), phycoerythrin-cyanine (PE-Cy)7-conjugated anti-CD8 (BD Biosciences), APC-conjugated anti-CD25 (eBioscience, San Diego, CA), PECy7-conjugated anti-CD127 (BD Biosciences), PE-Cy5-labeled anti-CD45RO (eBioscience), and APC-Cy7-labeled anti-CD45 (BD Biosciences) antibodies. The samples were incubated for $30 \mathrm{~min}$ at $4{ }^{\circ} \mathrm{C}$ in the dark. Erythrocytes were lysed using $1 x$ FACS lysing solution (BD Biosciences). Cells were washed with $1 \times$ PBS, fixed using $2 \%$ paraformaldehyde (Sigma-Aldrich, St. Louis), washed again, and resuspended in $300 \mu \mathrm{L}$ of PBS for acquisition on a flow cytometer (FACS LSR II, BD Biosciences). Intracellular staining with a PE-conjugated anti-FoxP3 antibody was performed after fixation and permeabilization using FoxP3 buffer kit (eBioscience).

Immunophenotyping of Th1, Th2, Th17, and Treg cells was performed on stimulated PBMCs. The cells were surface-stained with FITC-conjugated anti-CD3 (BD Biosciences) and PECy7labeled anti-CD8 (BD Biosciences) antibodies for $30 \mathrm{~min}$ at $4{ }^{\circ} \mathrm{C}$ in the dark. The surface-stained cells were fixed, permeabilized, washed, and incubated with the following intracellular antibodies: APC-conjugated anti-IFN- $\gamma$ (BD Biosciences), PE-labeled anti-IL-13 (BD Biosciences), PerCPCy5.5-conjugated anti-IL-17 (BD Biosciences), APC-conjugated anti-RORyt (eBioscience), and PElabeled anti-FoxP3 (eBioscience) for $40 \mathrm{~min}$ at $4{ }^{\circ} \mathrm{C}$. Fluorescence minus two was used as a control to enable correct gating during analysis followed by acquisition on a flow cytometer. Data were analyzed using the Diva software (version 6.1.2; BD Biosciences). PBMCs on FSC vs. SSC gate were gated for $\mathrm{CD}^{+} \mathrm{CD}^{-} \mathrm{T}$ cells, which were gated for IFN- $\gamma^{+}$Th1, IL-13 $13^{+}$Th2 cells from cocktail 1, and IL- $17^{+}$RORyt $^{+}$Th17 cells and FoxP3 ${ }^{+}$Treg cells from cocktail 2. The counts of Treg cells were determined by gating down CD25-bright FoxP3 ${ }^{+}$cells (negative for CD127) from $\mathrm{CD}^{+} \mathrm{CD}^{+} 5^{+}$ cells on whole blood. Absolute counts of lymphocyte subsets were calculated using their frequencies and whole-blood counts, the latter determined on a Beckman Coulter analyzer (Jersey City, NJ).

Estimation of urinary CD80 (uCD80)

Quantification of uCD80 was performed on ultrafiltered concentrated urine samples (Vivaspin-15 centrifugal concentrators, Sartorius Stedim Biotech, Goettingen). After rinsing spin columns with PBS, urine samples were centrifuged (Eppendorf, Westbury, $\mathrm{NY}$ ) at $4000 \times \mathrm{g}$ for $30 \mathrm{~min}$ at $20^{\circ} \mathrm{C}$. The concentrated sample (including CD80 of transmembrane origin, $54 \mathrm{kDa}$ ) was recovered from the upper panel of the ultrafilter column and stored at $-80^{\circ} \mathrm{C}$. 
The levels of uCD80 were measured using a commercially available ELISA kit (Bender MedSystems, Burlingame, CA), following the manufacturer's instructions. Standards and concentrated neat urine samples were run in duplicate. The final value of $u C D 80$ was based on the concentration factor and expressed as $\mathrm{ng} / \mathrm{g}$ of urinary creatinine.

\section{Statistical analysis}

Statistical analysis was performed using GraphPad Prism version 5 and Stata version 11; the results were expressed as median (interquartile range, IQR). Comparisons between pre- and postrituximab samples, and among different groups were made using Wilcoxon signed rank test and Mann-Whitney test, respectively; $P<0.05$ was considered significant.

\section{RESULTS}

The clinical and biochemical characteristics of patients $(n=18)$ and controls $(n=18)$ are shown in Table 1 . Of 8 patients who had a kidney biopsy, 7 had features suggestive of minimal-change disease and 1 had focal segmental glomerulosclerosis (FSGS); biopsy was not performed in the remaining patients. At 12months follow-up, 8 patients had relapsed after median time of 193.5 (134.3-258.5) days, while 10 were in remission.

Absolute counts of Th17 cells decreased; Treg cells increased after rituximab administration

Compared to controls, patients showed a higher proportion of IL$17^{+}$RORyt $^{+}$Th17 cells (patients at the baseline: median 1.3, IQR $0.7-1.5$ vs. control: $0.5,0.4-0.8 ; P<0.001$ ); absolute counts were

Table 1. Characteristics of patients with nephrotic syndrome and controls

\begin{tabular}{lll}
\hline Parameters & Patients, $N=18$ & Controls, $N=18$ \\
\hline Age at inclusion (years) & $10.0(6.8-13.0)$ & $8.6(5.8-11.1)$ \\
$\begin{array}{l}\text { Age at the onset of nephrotic } \\
\text { syndrome (years) }\end{array}$ & $2.0(1.2-3.2)$ years & - \\
$\begin{array}{l}\text { Boys; girls } \\
\text { Relapse; sustained remission at }\end{array}$ & $12 ; 6$ & $10 ; 8$ \\
12 months & $8 ; 10$ & - \\
Creatinine (mg/dl) & $0.5(0.5-0.6)$ & $0.6(0.48-0.73)$ \\
Protein (g/dl) & $6.5(5.8-7.0)$ & $7.4(7.0-7.5)$ \\
Albumin (g/dl) & $4.2(3.9-4.8)$ & $4.9(4.4-5.4)$ \\
Cholesterol (mg/dl) & $233(201.3-286.5)$ & $146(134-182.8)$ \\
Urine protein/creatinine ratio & $1.1(0.6-1.5)$ & $0.4(0.3-0.5)$ \\
(mg/mg) & & \\
Previous therapies & & - \\
Levamisole & 16 & - \\
$\begin{array}{l}\text { Cyclophosphamide: oral, } \\
\text { intravenous }\end{array}$ & 16,2 & - \\
$\begin{array}{l}\text { Mycophenolate mofetil } \\
\text { Cyclosporine, tacrolimus }\end{array}$ & 11 & - \\
Medication-related side effects & 2,4 & - \\
$\begin{array}{l}\text { Cushingoid features } \\
\text { Short stature (<-2 standard- } \\
\text { deviation score) }\end{array}$ & 15 & - \\
$\begin{array}{l}\text { Cataract, glaucoma } \\
\text { Hirsutism }\end{array}$ & 6,16 & - \\
$\begin{array}{l}\text { Hypertension } \\
\text { Hyperglycemia }\end{array}$ & 3 & - \\
& 10 & - \\
\hline
\end{tabular}

also higher (Table 2). The median proportion of Th17 cells reduced at 1 month to $0.7(0.3-1.1, P=0.035)$; the corresponding Th17 counts were also significantly lower $(P=0.0026$; Table 2$)$. The proportion of Th17 cells increased during relapse ( 1 month: 0.85 , $0.45-1.28$ vs. relapse: $1.0,0.85-1.48 ; P=0.035)$; similarly, absolute counts were also higher (Table 2). Among the non-relapsers, the proportions of Th17 cells were similar at 1 and 12 months. Furthermore, the proportion of CD4 ${ }^{+} \mathrm{CD} 25$ bright CD127- FoxP3 ${ }^{+}$ Treg cells was lower in patients than controls (patients at the baseline: 1.6, 1.2-2.2 vs. control: 4.3, 3.4-6.3; $P<0.0001$ ); the absolute counts were also lower $(16.1,11.6-19.3$ vs. 45.4 , and 31.4-59.6; $P<0.0001$; Table 2). The proportion of Treg cells increased to $4.1(2.8-5.8, P=0.0002) 1$ month following rituximab therapy; absolute counts were significantly higher (Table 2). In relapsers, the proportion of Treg cells decreased during relapse (1 month: 4.2, 2.7-6.1 vs. relapse: $2,1.2-3.5 ; P=0.0078$ ). Among non-relapsers, the proportions of Treg cells were comparable at 1 and 12 months.

Rituximab therapy reversed the ratio of Th17/Treg cells The median ratio of Th17/Treg cells during steroid-induced remission and before rituximab administration was higher in patients than controls (patients at baseline: 0.6, IQR 0.3-1.0 vs. controls: $0.1,0.1-0.2, P<0.001$ ). Figure 2 shows that the ratio decreased 1 month after rituximab treatment to a median of 0.2 (0.1-0.3; $P=0.006)$. In relapsers, the Th17/Treg cells ratio increased on occurrence of relapse (1 month: $0.2,0.1-0.3$ vs. relapse: $0.3,0.2-0.5 ; P=0.016)$. The ratios between relapsers and non-relapsers (relapse vs, remission after 12 months; $P=0.110$ ) and within non-relapsers ( 1 month vs. remission after 12 months; $P=0.106)$ were comparable.

Rituximab reduced the absolute counts of Th2 cells, with no significant changes in Th1 cells

The absolute count of Th2 cells $(P=0.0096$, Table 2$)$ but not Th1 cells $(P=0.638)$ was higher in patients than controls. Patients at relapse also had a higher proportion of Th2 cells than controls (relapse: $1.5,1.0-2.3$ vs. control: $1.0,0.5-1.3 ; P=0.0424$ ). Th2 cell count decreased after rituximab treatment $(P=0.0041$; Table 2); no significant differences were observed in Th1 counts. Among relapsers, counts of Th2 cells increased during relapse $(P=0.0078$, Table 2). There was no significant difference in counts of Th1 cells. Among non-relapsers, counts of Th1 and Th2 cells at 1 and 12 months were similar.

Th1/Th2 helper-cell ratio increased after rituximab administration Compared to controls, Th1/Th2 ratio was lower in patients (patients at baseline: 7.7, 3.2-13.2 vs. controls: 15.9, 10.5-20.4; $P=0.0018$, and at relapse: $8.7,6.6-13.4 ; P=0.037)$. The ratio increased 1 month after rituximab treatment to $14.0(6.6-24.5, P=$ 0.0102 ; Fig. 3). Th1/Th2 ratio decreased during relapse (1 month: $23.0,7.8-25.2$ vs. relapse: $8.7,6.6-14.0 ; P=0.023)$. The ratio was significantly lower during relapse (relapse: $8.7,6.6-13.4$ vs. nonrelapsers at 12 months: $17.5,11.7-21.6 ; P=0.033$ ). Among the non-relapsers, Th1/Th2 ratios were similar at 1 and 12 months and were comparable to controls.

$\mathrm{CD}^{+}$and $\mathrm{CD}^{+}{ }^{+}$T-cell counts decreased after rituximab administration

Compared to baseline, therapy with rituximab was associated with a significant decrease in counts of $\mathrm{CD}^{+}$helper (1124.0, 837.7-1407.0 vs. 754.0, 567.9-1272.0 cells $/ \mu \mathrm{L} ; P=0.0051), \mathrm{CD}^{+}$ cytotoxic (1162.0, 754.4-1807.0 vs. 866.4, 650.3-1531.0 cells/ $\mu \mathrm{L}$; $P=0.013)$, and $\mathrm{CD} 45 \mathrm{RO}^{+}$memory $(593.1,341.6-717.6$ vs. 442.8, 352.2-595.7 cells $/ \mu \mathrm{L} ; P=0.0059)$ T cells at 1 month. $\mathrm{CD}^{+}{ }^{+} \mathrm{T}$ cell counts in patients (at baseline and relapse) were comparable to controls. The count of $\mathrm{CD}^{+} \mathrm{T}$ cells was higher in patients than controls (patients baseline: 1162, 754.4-1807.0 vs. controls: 794.9, 
Table 2. Median (IQR) counts (cells/ $\mu \mathrm{L}$ ) of lymphocyte subsets and levels of urinary CD80 in patients with steroid-dependent nephrotic syndrome at baseline and following rituximab therapy

\begin{tabular}{llllll}
\hline & $\begin{array}{l}\text { Baseline } \\
(N=18)\end{array}$ & $\begin{array}{l}1 \text { month/ } \\
6 \text { months }(N=18)\end{array}$ & $\begin{array}{l}\text { Relapse } \\
(N=8)\end{array}$ & $\begin{array}{l}\text { Remission, } \\
12 \text { months }(N=10)\end{array}$ \\
\hline Th17 cells & $11(7-17)^{\mathrm{a}^{*}}$ & $5(3-11)^{\mathrm{b}^{*}}$ & $12(7-23)^{\mathrm{d}^{*}}$ & $6(4-10)$ & $\begin{array}{l}\text { Controls } \\
(N=18)\end{array}$ \\
T-regulatory cells & $16(12-19)^{\mathrm{a}^{* *}}$ & $33(23-55)$ & $24(12-33)$ & $41(25-63)^{f^{*}}$ & $45(4-8)^{\mathrm{g}^{* *}, \mathrm{~h}^{*}}$ \\
Th1 cells & $169(72-215)$ & $135(46-190)$ & $135(113-168)$ & $128(94-149)$ & $128(90-187)$ \\
Th2 cells & $16(12-26)^{\mathrm{a}^{* *}}$ & $8(5-14)^{\mathrm{b}^{*}}$ & $13(12-23)$ & $8(4-17)^{\mathrm{f}^{*}}$ & $11(5-16)^{\mathrm{g}^{*}}$ \\
B-memory cells & $98(60-157)^{\mathrm{a}^{* *}}$ & $14(6-21)^{\mathrm{c}^{*}}$ & $30(25-41)^{\mathrm{d}^{*}, \mathrm{e}^{*}}$ & $18(8-27)^{\mathrm{f}^{*}}$ & $79(57-121)^{\mathrm{h}^{* *}, \mathrm{i}^{* *}}$ \\
uCD80, ng/g creatinine & $45(37-155)^{\mathrm{a}^{* *}}$ & $23(6-56)^{\mathrm{b}^{* *}}$ & $354(236-1089)^{\mathrm{d}^{*}}$ & $13(8-182)$ & $53(7-78)^{\mathrm{h}^{* * *}}$ \\
\hline
\end{tabular}

Th T-helper cells, $u C D 80$ urinary CD80

a Baseline vs. 1 month

${ }^{\mathrm{b}} 1$ month vs. relapse

'6 months vs. relapse

${ }^{\mathrm{d}}$ Relapse vs. remission (12 months)

eBaseline vs. relapse

fBaseline vs. remission (12 months)

${ }^{9}$ Baseline vs. controls

${ }^{h}$ Relapse vs. controls

i 12 months vs. controls

${ }^{*} P<0.050,{ }^{* * *} P<0.005,{ }^{* * *} P<0.0005$

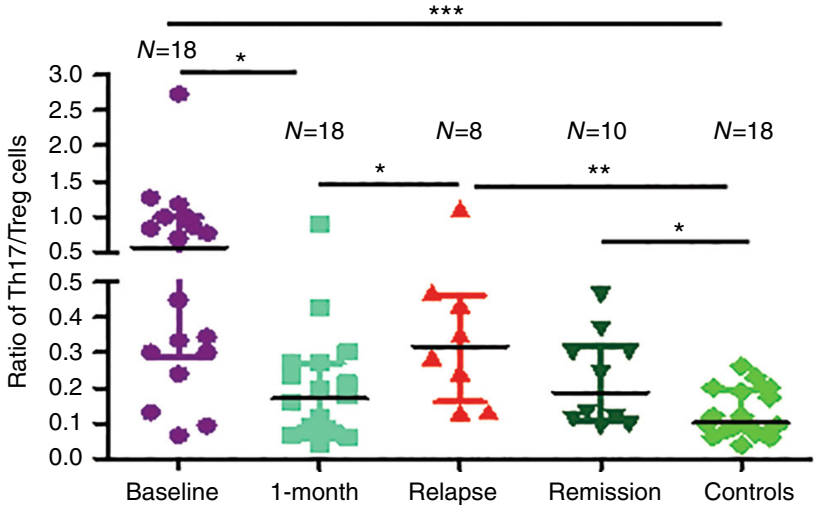

Fig. 2 Rituximab treatment is associated with reversal of Th17/Tregulatory (Treg) cells ratio. The ratio of Th17 to Treg cells (median, IQR) in patients at baseline, after 1 month, after 12 months at remission or before at relapse, and healthy controls. ${ }^{*} P<0.05$, ${ }^{* *} P<$ $0.005,{ }^{* *} P<0.0005$

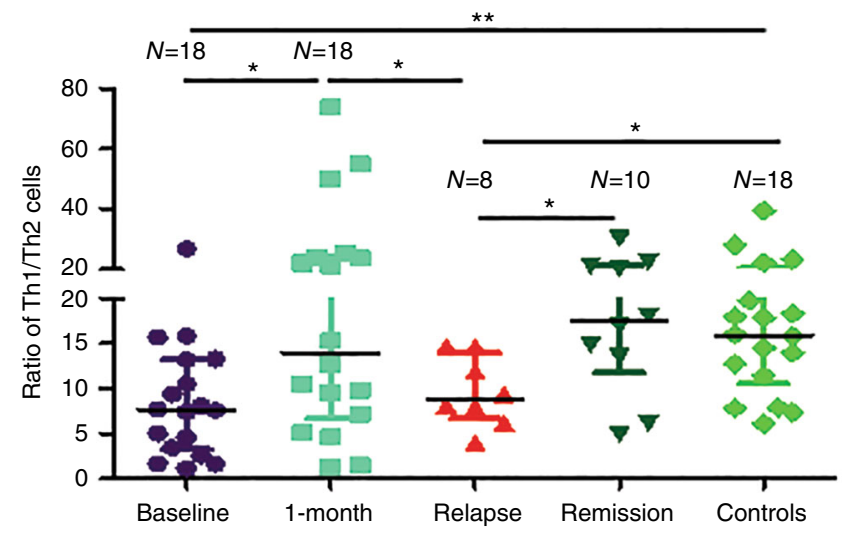

Fig. 3 Changes in the Th1/Th2 ratio following rituximab therapy in patients with steroid-dependent nephrotic syndrome. The ratio of Th1 to Th2 cells (median, IQR) in patients at baseline, after 1 month, after 12 months at remission or at relapse, and healthy controls. ${ }^{*} P<$ $0.05,{ }^{* *} P<0.005$
628.1-968.7; $P=0.037)$. Compared to baseline, the ratios of CD4/CD8 and naive/memory T cells did not change after 1 month of rituximab treatment.

B-cell repopulation was associated with the occurrence of relapse Sixteen of 18 patients with steroid dependence showed complete depletion of $\mathrm{CD} 19^{+} \mathrm{B}$ cells ( $<1 \%$ of lymphocytes). Two patients had incomplete depletion of $B$ cells. While one patient with 440 cells/ $\mu \mathrm{L}$ ( $10 \%$ CD $19^{+}$lymphocytes) at 1 month relapsed after 249 days, the second with 94 cells/ $\mu \mathrm{L}$ ( $2 \%$ CD $19^{+}$lymphocytes) at 1 month was in sustained remission for 12 months. B cells repopulated after a median time of 179.0 (60.3-184.5) days. B cells repopulated earlier in the eight relapsers $(60.0,32.0-122.0$ days) than in the non-relapsers (183.0, 180.5-190.0 days; $P=0.0002$; Fig. 4a).

Early reconstitution of memory $B$ cells was associated with relapse Compared to patients who were in remission at 6 months, the counts of $\mathrm{CD}_{2} 7^{+} \mathrm{CD} 19^{+}$memory $\mathrm{B}$ cells were significantly higher at relapse (Table 2, Fig. $4 b, c)$. The absolute numbers of memory $B$ cells were similar between 6 and 12 months in patients who maintained sustained remission (Table 2). The ratio of naive/ memory B cells was lower in relapsers $(9.0,3.0-11.6)$ than in nonrelapsers $(16.2,13.1-28.2 ; P=0.0097)$.

Median B-regulatory cell counts were lower in patients at the baseline than in controls $(6.9,4.9-14.9$ vs. 17.2 , and 7.8-29.9; $P=$ 0.012). Also, compared to baseline, the proportions (but not the counts) of $\mathrm{CD}^{+} \mathrm{CD}^{+} 9^{+}$B-regulatory cells were increased significantly after 6 months of rituximab treatment (1.8, 1.2-2.0 to $3.8,2.0-6.2 \% ; P=0.002$ ).

Urinary CD80 (uCD80) decreased after rituximab administration The levels of uCD80 were significantly lower after 1 month of rituximab treatment compared to baseline ( $P=0.0039$, Table 2). uCD80 levels were significantly higher at relapse than levels in patients in sustained remission at 12 months (Table 2). Although there was a trend of higher uCD80 excretion at 1 month (42.0, 23.0-93.0 ng/g creatinine) in patients who relapsed during 12-months follow-up compared to those in sustained remission (8.1, 5.2-33.6), the difference was not significant $(P=0.070)$. 

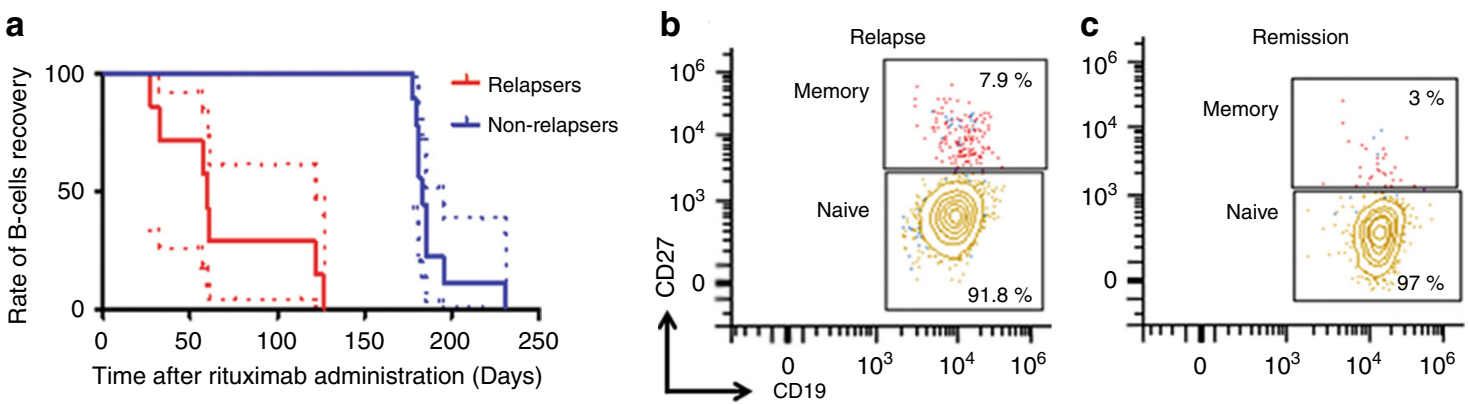

Fig. 4 Early recovery of $\mathrm{CD} 19^{+} \mathrm{B}$ lymphocytes and $\mathrm{CD} 27^{+}$memory $\mathrm{B}$ cells following rituximab administration is associated with relapse. a Kaplan-Meier analysis showing the association of B-lymphocyte repopulation to the relapse of a nephrotic syndrome. The median time of B-cell repopulation after rituximab-induced depletion was shorter in relapsers (60, IQR 32-122 days) compared to the non-relapsers (183, IQR 180.5-190 days); hazard ratio 39.1 (95\% Cl 7.3, 210.3); log rank $P<0.0001$. Dotted lines represent $95 \%$ confidence limits. b, c Representative flow cytometry plots for naive $\left(\mathrm{CD} 27^{-}\right)$and memory $\left(\mathrm{CD} 27^{+}\right) \mathrm{B}$ cells gated from the $\mathrm{CD} 19^{+} \mathrm{CD} 45^{+}$cells (not shown) during relapse $(\mathbf{b})$ and at remission at 12 months (c)

\section{DISCUSSION}

A lack of understanding regarding the mechanism of rituximabinduced remission in patients with SDNS makes therapy largely empirical. The present study examined the effects of rituximab on B- and T-lymphocyte subsets in such patients. We performed immunophenotyping of lymphocyte subsets in patients with a nephrotic syndrome at multiple time points after the administration of rituximab. Therapy with prednisolone was rapidly tapered; none of the patients were receiving other immunosuppressive medications. As has been observed in the context of inflammatory diseases; ${ }^{16,24}$ we confirm that rituximab significantly reduces the counts of circulating IL-17-producing Th17 cells and increases FoxP3-expressing Treg cells. The effects of rituximab on Th17-Tregulatory lymphocytes are consistent with accumulating evidence in other T-cell-mediated disorders, including rheumatoid arthritis $^{21}$ and systemic lupus erythematosus. ${ }^{15}$

Multiple researchers propose that an imbalance in Th17/Treg cells has an important role in the pathogenesis of a nephrotic syndrome. ${ }^{7,8,22}$ Impaired T-regulatory function with normal proportions of cells is also reported. ${ }^{25}$ Our data show that the ratio of Th17/Treg cells reduced 1 month following therapy with rituximab and increased in patients who relapsed during 12months' follow-up. Therapy with two doses of rituximab resulted in a decrease in the numbers of $\mathrm{IL}-17^{+}$Th17 and an increase in Treg cells; the former increased during relapses of the illness. However, the mechanism by which Th17 cells lead to proteinuria is not clear. Wang et al. showed that murine podocytes, when exposed in vitro to recombinant IL-17 show an altered expression of podocalyxin with destabilization of the cytoskeleton. ${ }^{8}$ Transdifferentiation of naive or Treg cells to Th17 cells may occur following the exposure to unknown antigens, viral particles, or permeability factor(s). ${ }^{9}$

It has also been postulated that Th1/Th2 imbalance might have a pathogenic role in the disease. Steroid-sensitive nephrotic syndrome is associated with a tendency to atopy, Th2 polarization, and increased circulating levels of the cytokines, IL-4 and IL-13, and no change in IFN- $\gamma$-expressing Th1 cells during relapses. 5,6,26 mRNA transcripts of the kidneys of buffalo/Mna rat, an animal model of FSGS, show upregulated Th2 (IL-10 and IL-13) and downregulated Th1 (IL-2 and IFN- $\gamma$ ) cytokines. ${ }^{27}$ Other workers have shown that transfection of IL-13 in rats results in podocyte foot-process effacement, proteinuria, hypoalbuminemia, and hyperlipidemia. ${ }^{28}$ Findings from the present study support earlier reports that therapy with rituximab was associated with a significant decline in the number of $\mathrm{IL}_{-13}+3^{+} \mathrm{Th} 2$ cells, which increased during a subsequent relapse. ${ }^{26-28}$ The change in the number of IL-13 $3^{+}$Th2, but not IFN- $\gamma^{+}$Th1 cells resulted in an increase in Th1/Th2 ratio 1 month following therapy, which reversed during relapse. This effect of rituximab on the ratio of Th1/Th2 due to Th2, but not Th1 cells has to our knowledge, not been reported.

The present findings show that while B cells depleted following therapy with rituximab, their faster recovery predicts relapses of the disease. Sato et al. also showed that B-cell recovery was associated with a higher risk of relapses; ${ }^{29}$ similar findings are reported by others. ${ }^{23,30}$ The time to recovery of $B$ cells varies across studies, but ranges between 6 and 20.5 months. ${ }^{18,31}$ Data from most studies, including the present, suggest that relapses of a nephrotic syndrome are uncommon in patients with B-cell depletion.

Kim et al. ${ }^{32}$ recently highlighted the importance of B cells and their cytokines in mediating proteinuria. Through in vitro experiments, they confirm that rituximab does not show binding to sphingomyelin phosphodiesterase acid-like 3b (SMPDL3b) receptor on the human embryonic kidney, 293T cells. Their study suggests that the efficacy of rituximab in a nephrotic syndrome is independent of its ability to directly modulate the podocytes.

Our finding of higher numbers of memory B cells in relapsers than non-relapsers is consistent with those reported previously. ${ }^{23}$ Colucci et al. showed that while rituximab depletes pathogenic memory B cells, their delayed reconstitution may contribute to sustained remission. They also proposed that newly recovered memory B cells in non-relapsers were mostly nonpathogenic, as they had undergone central immune tolerance. The pathogenicity of memory B cells is also defined in terms of providing antiapoptotic signals for viral replication. ${ }^{33}$ Epstein-Barr virus (EBV) resides lifelong in resting-memory $B$ cells; in immunocompromised individuals, these $B$ cells release the virus during the lytic phase of infection. Dossier et al. hypothesized that anti-EBNA1 antibodies may cause an instability of the podocyte cytoskeleton by cross- reacting with podocyte proteins; clearance of these antibodies results in recovery of proteinuria. ${ }^{33}$ None of our patients showed any known viral infection at the time of relapse. Long-term memory B-cell depletion may also be detrimental. Persistent depletion of these cells and the resultant hypogammaglobulinemia predisposes patients to a high risk of infections. ${ }^{34}$ Immune response to vaccines is also dependent on maintenance of circulating antibody levels by memory B cells.

Rituximab therapy might affect the frequency of Th17 cells by depleting B cells and their cytokines (IL-6 and TGF- $\beta$ ), which promote the differentiation of Th17 cells. ${ }^{10}$ Rituximab might directly bind to Th17 cells via the SMPDL3b receptor, and inhibit mTORC1-mediated IL-17 production by modulating its transcription factor, STAT3. ${ }^{35,36}$ Rituximab is also believed to directly inhibit mast cells dependent amplification of Th17 lymphocytes, by binding to mast cell FcERI that has structural similarities to 
CD20. ${ }^{24,37}$ B cells normally inhibit the expansion of Treg cells and amplify effector T-cell functions. ${ }^{38,39}$ B-cell-activating factors promote apoptosis of Treg cells, and inhibit their expansion in an IL-2-dependent manner. ${ }^{38}$ In B-cell-depleted mice, the proportions and function of Treg cells is enhanced. Other mechanisms underlying rituximab-induced response involve the inhibition of CD40-CD40L costimulatory interactions between B and T cells, with failure of conversion of Treg cells into an inflammatory phenotype. $^{38}$

This is the first study that shows the effect of rituximab on uCD80 excretion. The observation of elevated uCD80 levels during relapse of a nephrotic syndrome is consistent with the findings by Garin et al. ${ }^{12}$ Treg cells are proposed to regulate the expression of CD80 on antigen-presenting cells via soluble forms of cytotoxic Tlymphocyte-associated protein 4 (CTLA-4) and IL-10. ${ }^{11}$ The increase in Treg cells after rituximab therapy might thus be the explanation for the decrease in uCD80 excretion. Consistent with this assumption, patients during relapse usually show reduced levels of circulating CTLA-4 and IL-10. ${ }^{40}$ Finally, Garin et al. ${ }^{12}$ hypothesized that circulating IL-13 might induce the expression of CD80 on podocytes. Decreased expression of the cytokine on PBMCs after rituximab treatment might thus be associated with reduced uCD80 levels.

In conclusion, findings from this study suggest that rituximabinduced B-cell depletion has significant effects on helper T cells, chiefly Th17, Treg, and Th2 cells. We also observed reduced uCD80 excretion after rituximab treatment. Our data confirm the association between early repopulation of total $B$ and memory $B$ cells with occurrence of relapse. These findings underscore the importance of the immune system in the pathogenesis of a nephrotic syndrome. Further studies are necessary to delineate the precise interactions between $B$ and $T$ lymphocytes, and the effect of B-cell-derived humoral response on the pathogenesis of the illness. Investigations are also required to determine and validate the risk factors for relapses that follow treatment with rituximab.

\section{ACKNOWLEDGEMENTS}

D.B., A.S., and A.B. conceived the study. D.B. performed all the experiments. A.B., A.S., and P.H. contributed clinical samples. D.B. and A.B. wrote and edited the manuscript; A.B. supervised the project. All authors read and approved the manuscript. This work was supported in part by grants from the Indian Council of Medical Research (5/4/712/1-NCD-II) and the British Council (UKIERI-TRP-2012/13-001) to A.B.

\section{ADDITIONAL INFORMATION}

Competing interests: The authors declare no competing interests.

Publisher's note: Springer Nature remains neutral with regard to jurisdictional claims in published maps and institutional affiliations.

\section{REFERENCES}

1. Greenbaum, L. A., Benndorf, R. \& Smoyer, W. E. Childhood nephrotic syndromecurrent and future therapies. Nat. Rev. Nephrol. 12, 445-458 (2012).

2. Elie, V., Fakhoury, M., Deschenes, G. \& Jacqz-Aigrain, E. Physiopathology of idiopathic nephrotic syndrome: Lessons from glucocorticoids and epigenetic perspectives. Pediatr. Nephrol. 27, 1249-1256 (2012)

3. Garin, E. H., Blanchard, D. K., Matsushima, K. \& Djeu, J. Y. IL-8 production by peripheral blood mononuclear cells in nephrotic patients. Kidney Int. 45, 1311-1317 (1994).

4. Marie, J. C. et al. Mechanism of measles virus-induced suppression of inflammatory immune responses. Immunity 14, 69-79 (2001).

5. Audard, V. et al. Minimal change nephrotic syndrome and classical Hodgkin's lymphoma: report of 21 cases and review of the literature. Kidney Int. 69, 2251-2260 (2006).

6. Abdel-Hafez, M., Shimada, M., Lee, P. Y., Johnson, R. J. \& Garin, E. H. Idiopathic nephrotic syndrome and atopy: is there a common link? Am. J. Kidney Dis. 54, 945-953 (2009).
7. Shao, X. S. et al. The prevalence of Th17 cells and FOXP3 regulate T cells (Treg) in children with primary nephrotic syndrome. Pediatr. Nephrol. 24, 1683-1690 (2009).

8. Wang, L. et al. The role of Th17/IL-17 in the pathogenesis of primary nephrotic syndrome in children. Kidney Blood Press. Res. 37, 332-345 (2013).

9. Komatsu, N. et al. Pathogenic conversion of Foxp $3^{+} \mathrm{T}$ cells into $\mathrm{TH} 17$ cells in autoimmune arthritis. Nat. Med. 20, 62-68 (2014).

10. Eisenstein, E. M. \& Williams, C. B. The $T(\mathrm{reg}) / \mathrm{Th} 17$ cell balance: a new paradigm for autoimmunity. Pediatr. Res. 65, 26R-31R (2009).

11. Walker, L. S. K. Treg and CTLA-4: two intertwining pathways to immune tolerance. J. Autoimmun. 45, 49-57 (2013).

12. Garin, E. H. et al. Urinary CD80 is elevated in minimal change disease but not in focal segmental glomerulosclerosis. Kidney Int. 78, 296-302 (2010).

13. Smith, M. R. Rituximab (monoclonal anti-CD20 antibody): mechanisms of action and resistance. Oncogene 22, 7359-7368 (2003).

14. van Oers, M. H. et al. Rituximab maintenance improves clinical outcome of relapsed/resistant follicular non-Hodgkin lymphoma in patients both with and without rituximab during induction: Results of a prospective randomized phase 3 inter group trial. Blood 108, 3295-3301 (2006).

15. Gunnarsson, I. et al. Histopathologic and clinical outcome of rituximab treatment in patients with cyclophosphamide-resistant proliferative lupus nephritis. Arthritis Rheum. 56, 1263-1272 (2007).

16. Van de Veerdonk, F. L. et al. The anti-CD20 antibody rituximab reduces the Th17 cell response. Arthritis Rheum. 63, 1507-1516 (2011).

17. lijima, K. et al. Rituximab for childhood-onset, complicated, frequently relapsing nephrotic syndrome or steroid-dependent nephrotic syndrome: A multicentre, double-blind, randomised, placebo-controlled trial. Lancet 384, 1273-1281 (2014).

18. Sinha, A. et al. Efficacy and safety of rituximab in children with difficult-to-treat nephrotic syndrome. Nephrol. Dial. Transplant. 30, 96-106 (2015).

19. Gulati, A. et al. Efficacy and safety of treatment with rituximab for difficult steroidresistant and -dependent nephrotic syndrome. Clin. J. Am. Soc. Nephrol. 5, 2207-2212 (2010).

20. Sinha, A. \& Bagga, A. Rituximab therapy in nephrotic syndrome: implications for patients' management. Nat. Rev. Nephrol. 9, 154-169 (2013).

21. Leandro, M. J., Cambridge, G., Ehrenstein, M. R. \& Edwards, J. C. Reconstitution of peripheral blood B cells after depletion with rituximab in patients with rheumatoid arthritis. Arthritis Rheum. 54, 613-620 (2006).

22. Chan, C. Y. et al. Lymphocyte activation markers as predictors of responsiveness to rituximab among patients with FSGS. Clin. J. Am. Soc. Nephrol. 11, 1360-1368 (2016). 8.

23. Colucci, M. et al. B cell reconstitution after rituximab treatment in idiopathic nephrotic syndrome. J. Am. Soc. Nephrol. 27, 1811-1822 (2016).

24. Ciccia, F. et al. Rituximab modulates IL-17 expression in the salivary glands of patients with primary Sjogren's syndrome. Rheumatology 53, 1313-1320 (2014).

25. Araya, $C$. et al. T regulatory cell function in idiopathic minimal lesion nephrotic syndrome. Pediatr. Nephrol. 24, 1691-1698 (2009).

26. Yap, H. K. et al. Th1 and Th2 cytokine mRNA profiles in childhood nephrotic syndrome evidence for increased IL-13 mRNA expression in relapse. J. Am. Soc. Nephrol. 10, 529-537 (1999).

27. Le Berre, L. et al. Renal macrophage activation and Th2 polarization precedes the development of nephrotic syndrome in Buffalo/Mna rats. Kidney Int. 68, 2079-2090 (2005).

28. Lai, K. W. et al. Overexpression of interleukin-13 induces minimal-change-like nephropathy in rats. J. Am. Soc. Nephrol. 18, 1476-1485 (2007).

29. Sato M., Kamei K., Ogura M., Ishikura K., Ito S. Relapse of nephrotic syndrome during post-rituximab peripheral blood B-lymphocyte depletion. Clin Exp Nephrol. 2017;22 https://doi.org/10.1007/s10157-017-1415-8.

30. Sellier-Leclerc, A. L. et al. Rituximab in steroid-dependent idiopathic nephrotic syndrome in childhood-follow-up after CD19 recovery. Nephrol. Dial. Transplant. 27, 1083-1089 (2012).

31. Ravani, P. et al. Rituximab in children with steroid-dependent nephrotic syndrome: a multicenter, open-label, noninferiority, randomized controlled trial. J. Am. Soc. Nephrol. 26, 2259-2266 (2015).

32. Kim, A. H. et al. B cell-derived IL-4 acts on podocytes to induce proteinuria and foot process effacement. JCI Insight 2, e81836 (2017).

33. Dossier, C., Jamin, A. \& Deschênes, G. Idiopathic nephrotic syndrome: the EBV hypothesis. Pediatr. Res. 81, 233-239 (2017).

34. Quartuccio, L. et al. Long-term effects of rituximab in rheumatoid arthritis: clinical, biologic, and pharmacogenetic aspects. Ann. N. Y. Acad. Sci. 1173, 692-700 (2009).

35. Bai, A. \& Robson, S. Beyond ecto-nucleotidase: CD39 defines human Th17 cells with CD161. Purinergic Signal 11, 317-319 (2015).

36. Ravani, P., Bonanni, A., Rossi, R., Caridi, G. \& Ghiggeri, G. M. Anti-CD20 antibodies for idiopathic nephrotic syndrome in children. Clin. J. Am. Soc. Nephrol. 11, 710-720 (2016). 
Rituximab modulates T- and B-lymphocyte subsets and urinary CD80...

D Bhatia et al.

526

37. Hupp, K., Siwarski, D., Mock, B. A. \& Kinet, J. P. Gene mapping of the three subunits of the high affinity FcR for lgE to mouse chromosomes 1 and 19. J. Immunol. 143, 3787-3791 (1989).

38. Olson, T. S. et al. Expanded B-cell population blocks regulatory T cells and exacerbates ileitis in a murine model of Crohn disease. J. Clin. Invest. 114, 389-398 (2004).
39. Moulin, V. et al. B lymphocytes regulate dendritic cell (DC) function in vivo: increased interleukin 12 production by DCs from B cell-deficient mice results in $T$ helper cell type 1 deviation. J. Exp. Med. 192, 475-482 (2000).

40. Tsuji, S. et al. Regulatory T cells and CTLA-4 in idiopathic nephrotic syndrome. Pediatr. Int. 59, 643-646 (2017). 